\title{
Wogonin triggers apoptosis in human osteosarcoma U-2 OS cells through the endoplasmic reticulum stress, mitochondrial dysfunction and caspase-3-dependent signaling pathways
}

\author{
CHIN-CHUNG LIN ${ }^{1,3}$, CHAO-LIN KUO ${ }^{4}$, MAU-HWA LEE ${ }^{2}$, KUANG-CHI LAI $^{5,10}$, JING-PIN LIN ${ }^{6}$, JAI-SING YANG ${ }^{8}$, \\ CHUN-SHU YU ${ }^{7}$, CHI-CHENG LU ${ }^{11}$, JO-HUA CHIANG ${ }^{11}$, FU-SHIN CHUEH ${ }^{12}$ and JING-GUNG CHUNG ${ }^{9,13}$ \\ Departments of ${ }^{1}$ Chinese Medicine, ${ }^{2}$ Internal Medicine, Fong-Yuan Hospital, Department of Health, Executive Yuan, \\ Taichung 420; ${ }^{3}$ School of Medicine and Nursing, HungKuang University, Taichung 433; Schools of ${ }^{4}$ Chinese Pharmaceutical \\ Sciences and Chinese Medicine Resources, ${ }^{5}$ Medicine, ${ }^{6}$ Chinese Medicine, ${ }^{7}$ Pharmacy, and Departments of ${ }^{8}$ Pharmacology, \\ ${ }^{9}$ Biological Science and Technology, China Medical University, Taichung 404; ${ }^{10}$ Department of Surgery, China Medical \\ University Beigang Hospital, Yunlin 651; ${ }^{11}$ Department of Life Sciences, National Chung Hsing University, Taichung 402; \\ Departments of ${ }^{12}$ Health and Nutrition Biotechnology, ${ }^{13}$ Biotechnology, Asia University, Taichung 413, Taiwan, R.O.C.
}

Received January 27, 2011; Accepted March 30, 2011

DOI: 10.3892/ijo.2011.1027

\begin{abstract}
Wogonin (5,7-dihydroxy-8-methoxyflavone) is a flavone constituent of Scutellaria baicalensis with various beneficial biological activities and it has been shown to have tumor therapeutic potential in vitro and in vivo. The purpose of this study was to investigate the effects of wogonin in a human osteosarcoma cell line (U-2 OS). Results showed that a dose- and time-dependent reduction occurred in cell viability after exposure to wogonin in U-2 OS cells. Increasing the levels of reactive oxygen species (ROS) and $\mathrm{Ca}^{2+}$ but decreasing the levels of mitochondrial membrane potential $(\Delta \Psi m)$ were examined in wogonin-treated U-2 OS cells. Flow cytometric assay indicated that wogonin induced sub-G1 phase (apoptosis) and increased caspase- 3 activity in examined cells. Wogonin-induced apoptosis in U-2 OS cells was also confirmed by 4',6-diamidino-2-phenylindole (DAPI) staining. Also, results from Western blotting indicated that wogonin increased the levels of Bad, Bax, cytochrome $c$, cleaved caspase-9, cleaved caspase-3, AIF, Endo G, Fas/CD95, caspase-8, GADD153, GRP78, ATF-6 $\alpha$, calpain 1, calpain 2 and caspase- 4 then leading to cell apoptosis. In conclusion, wogonin induced ROS production and intracellular $\mathrm{Ca}^{2+}$, and altered the levels of anti- (Bcl-2) and pro- (Bad and Bax) apoptotic proteins. Wogonin-induced apoptosis in U-2 OS cells was through the activation of caspase-3. In conclusion,
\end{abstract}

Correspondence to: Professor Jing-Gung Chung, Department of Biological Science and Technology, China Medical University, No. 91, Hsueh-Shih Road, Taichung 40402, Taiwan, R.O.C.

E-mail: jgchung@mail.cmu.edu.tw

Key words: wogonin, U2-OS human osteosarcoma cells, apoptosis, unfolded protein response, caspase activation these are the first findings to show wogonin-induced cytotoxic effects through induction of apoptotic cell death and ER stress in U-2 OS cells. The potent in vitro antitumor activities suggest that wogonin could be developed for the treatment of human osteosarcoma in the future.

\section{Introduction}

Cancer is the first leading cause of death worldwide. In USA, one in every four human deaths is from cancer. Apoptosis is one of the goals of cancer treatment. The characteristics of apoptosis can be the cell shrinkage, blebbing of the plasma membrane, apoptotic body and chromatin condensation that are associated with cleavage of DNA into ladders $(1,2)$. Other reports indicated that human malignant tumor cells respond to some effective therapeutic treatments and they could lead to decrease ability to undergo apoptosis $(3,4)$. Therefore, further development of agents that might induce or enhance the occurrence of apoptosis seems to be a promising strategy in the treatment of cancer. Successful treatment of cancer with chemotherapeutic agents is largely dependent on their ability to trigger cell death in tumor cells especial to induce apoptosis of cancer cells. Therefore, novel inducers of apoptosis could provide new therapeutic approaches for anticancer design.

Substantial evidence has demonstrated that certain phytochemicals present in medicinal herbs exert anti-tumorigenic activity by inducing apoptosis in cancer cells. Flavonoids, one of the most common active ingredients of medicinal herbs, possess pharmacological properties including anti-infammatory $(5,6)$, antioxidant $(7)$, and antitumor $(8,9)$ activities. Wogonin (5,7-dihydroxy-8-methoxyflavone, $\mathrm{C}_{16} \mathrm{H}_{12} \mathrm{O}_{5}$ ) is one of the active ingredients extracted from the roots of Scutellaria baicalensis Georgi. It has been reported that wogonin induced apoptosis in many tumor cells such as human breast cancer cell lines (8), prostate cancer cells (10), hepatocellular carcinoma SK-HEP-1 cells (11), promyeloleukemic cells (10) and ovarian 
cancer A2780 cells (12) and it suppressed tumor cells growth (13).

However, knowledge of the molecular mechanisms in wogonin-induced apoptosis of U-2 OS human osteosarcoma cells is unclear and it remains to be delineated. The purpose of this research is to conduct a series of experiments that afford further insights into mechanisms underlying the apoptotic action of wogonin on human osteosarcoma U-2 OS cells inclusive of cytotoxicity, induction of apoptosis and protein levels which are involved in apoptotic cell death. We also provide evidence suggesting that wogonin caused apoptosis through the ER stress, mitochondrial and caspase-3 signaling pathway in vitro.

\section{Materials and methods}

Chemicals and reagents. Wogonin, dimethyl sulfoxide (DMSO), propidium iodide (PI), Triton X-100 and trypan blue were purchased from Sigma-Aldrich Corp. (St. Louis, MO, USA). McCoy's 5A medium, penicillin-strptomycin, trypsin-EDTA, fetal bovine serum (FBS) and L-glutamine were obtained from Invitrogen Life Technologies (Carlsbad, CA, USA). The antibodies against $\mathrm{Bad}, \mathrm{Bax}, \mathrm{Bcl}-2$, cytochrome $c$, caspase-9 and caspase-3, AIF, Endo G, Fas/CD95, caspase-8, GADD153, GRP78, ATF-6 $\alpha$, calpain 1, calpain 2 and caspase-4 were obtained from Santa Cruz Biotechnology Inc. (Santa Cruz, CA, USA). Caspase-3 substrate assay kit (PhiPhiLux-G1D2) was bought from OncoImmunin, Inc. (Gaithersburg, MD, USA).

U-2 OS human osteosarcoma cells. The U-2 OS cell line was purchased from the Food Industry Research and Development Institute (Hsinchu, Taiwan). Cells were cultured in $75 \mathrm{~cm}^{2}$ tissue culture flasks in McCoy's 5A medium with $2 \mathrm{mM}$ L-glutamine, 10\% FBS, $100 \mathrm{U} / \mathrm{ml}$ penicillin and $100 \mu \mathrm{g} / \mathrm{ml}$ streptomycin and grown at $37^{\circ} \mathrm{C}$ under a humidified $5 \% \mathrm{CO}_{2}$ atmosphere (14).

Determinations of cell viability and morphological changes of U-2 OS cells. The U-2 OS cells were seeded into 12-well plates at a density of $2 \times 10^{5}$ cells/well for $24 \mathrm{~h}$. Then cells in each well were treated with $0,10,50,75,100$ and $150 \mu \mathrm{M}$ wogonin, while only adding $1 \%$ DMSO (solvent) for the control regimen and grown at $37^{\circ} \mathrm{C}, 5 \% \mathrm{CO}_{2}$ and $95 \%$ air for 24 and $48 \mathrm{~h}$. After treatment, the number of viable cells was determined with a flow cytometer (FACSCalibur, BectonDickinson, Franklin Lakes, San Jose, CA, USA) equipped with an argon ion laser at $488 \mathrm{~nm}$ wavelength as described elsewhere $(15,16)$. The cell morphology was examined and photographed under a phase-contrast microscope as described previously $(17,18)$.

Determinations of DNA content in U-2 OS cells. Cells $\left(2 \times 10^{5}\right.$ cells/well) placed in 12-well plates were treated with $75 \mu \mathrm{M}$ wogonin for 24- and 48-h exposure. For apoptosis assay, the cells were harvested by centrifugation, washed with phosphatebuffered saline (PBS) and fixed with $70 \%$ ethanol at $-20^{\circ} \mathrm{C}$ overnight. Cells were washed twice, re-suspended in PBS containing $40 \mu \mathrm{g} / \mathrm{ml}$ PI and $0.1 \mathrm{mg} / \mathrm{ml}$ RNase A and $0.1 \%$ Triton X-100 in a dark room for $30 \mathrm{~min}$ at $37^{\circ} \mathrm{C}$, and analyzed by flow cytometry. The sub-G1 group (apoptosis) was determined as described previously $(16,19)$. For DAPI staining, cells were stained by DAPI (4',6-diamidino-2-phenylindole, Molecular Probes/Invitrogen Life Technologies) at the concentration of $300 \mathrm{nmol} / 1 \mathrm{DPAI}$ for $30 \mathrm{~min}$ at $37^{\circ} \mathrm{C}$. Then nuclear morphology or apoptotic bodies were visualized, examined and photographed by fluorescence microscopy $(20,21)$.

Measurements of reactive oxygen species (ROS), the level of mitochondrial membrane potential $(\Delta \Psi m)$ and intracellular $\mathrm{Ca}^{2+}$ release in $U-2$ OS cells. Cells $\left(2 \times 10^{5}\right.$ cells/well) placed into 12 -well plates were treated with or without $75 \mu \mathrm{M}$ wogonin for 1, 3, 6, 12 and 24 h to detect the changes of ROS, $\Delta \Psi m$ and $\mathrm{Ca}^{2+}$, respectively. The cells from each treatment were individually harvested and washed with PBS twice, re-suspended in $500 \mu 1$ of 2,7-dichlorodihydrofluorescein diacetate (DCFH-DA) (Invitrogen) (10 $\mu \mathrm{M})$ for ROS, 3,3'-dihexyloxacarbocyanine iodide ( DiOC $_{6}$ ) (Invitrogen) $(1 \mu \mathrm{mol} / \mathrm{l})$ for $\Delta \Psi m$ and Fluo-3/AM $(2.5 \mu \mathrm{g} / \mathrm{ml})$ for $\mathrm{Ca}^{2+}$ release. Cells then were incubated at $37^{\circ} \mathrm{C}$ for $30 \mathrm{~min}$ and were analyzed by flow cytometry as described previously (22-24).

Caspase-3 activity assay in U-2 OS cells. Cells (1x105 cells/ well) in 12-wells plates were exposed to $75 \mu \mathrm{M}$ wogonin for 6 , 12, 24 and 48 h. Caspase-3 activity was assessed by flow cytometry. The cells were harvested and washed twice for determining of the activity of caspase-3 by using a substrate (PhiPhiLux-G1D2, OncoImmunin, Inc.) following the manufacturer's protocol, and then determined by using flow cytometric assay as described previously $(20,25)$.

Western blotting for examining the protein levels associated with apoptosis in U-2 OS cells. Cells $\left(2 \times 10^{6}\right.$ cells/well) placed in $10-\mathrm{cm}$ culture dish were treated with $75 \mu \mathrm{M}$ wogonin and incubated for $0,6,12,24$ and $48 \mathrm{~h}$. Then cells were harvested and were lysed in the PRO-PREP ${ }^{\mathrm{TM}}$ protein extraction solution (iNtRON Biotechnology, Seongnam, Gyeonggi-Do, Korea). The cell lysates were centrifuged at $13000 \mathrm{~g}$ at $4^{\circ} \mathrm{C}$ and the supernatant was collected for Western blot analysis, which was measured for protein concentration by using the Bio-Rad protein assay kit (Bio-Rad Laboratories, Hercules, CA, USA). The equal aliquots containing $50 \mu \mathrm{g}$ of each lane were separated by $10 \%$ sodium dodecyl sulfate polyacrylamide gel electrophoresis (SDS-PAGE) followed by electro-transfer onto PVDF membranes (Immobilon-P; Millipore, Bedford, MA, USA), and Ponceau S (Sigma-Aldrich Corp.) was used to identify the transferred proteins. The membranes were blocked by incubating in 5\% non-fat milk for nonspecific binding sites. Specific antibodies were purchased from Santa Cruz Biotechnology, Inc. Horseradish peroxidase-conjugated goat anti-rabbit or anti-mouse IgG (Millipore, Billerica, MA, USA) was used as a secondary antibody for enhanced ECL chemiluminescence reagent (Millipore) as described previously $(24,26)$. Immunoblotting for examining the effects of wogonin on Bad, Bax, Bcl-2, cytochrome $c$, caspase-9 and -3 active form, AIF, Endo G, Fas/CD95, caspase-8, GADD153, GRP78, ATF-6 $\alpha$, calpin 1, calpin 2, and caspase-4 were performed. Quantifying the relative abundance of each band was done by using NIH ImageJ 1.43 software for Windows (27). 
A

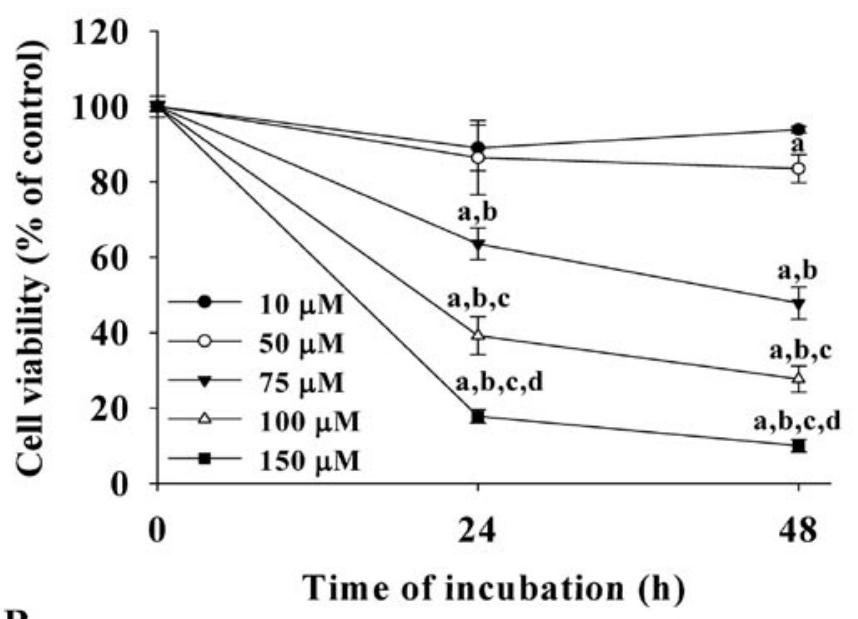

B
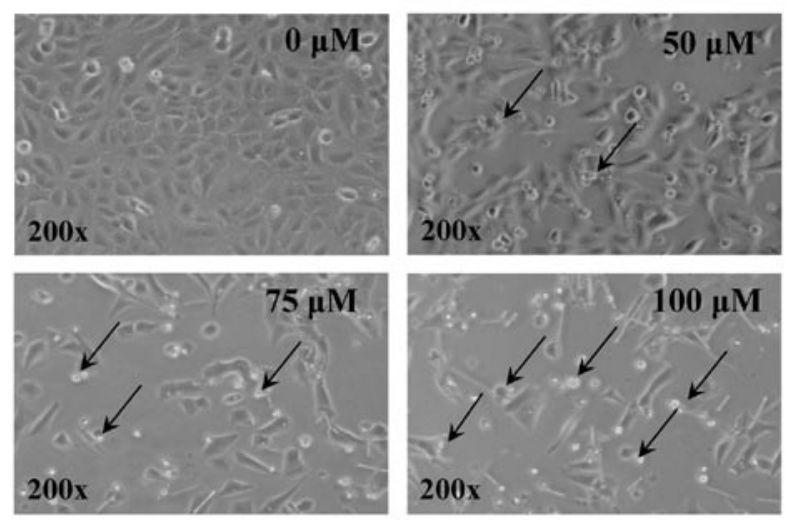

Figure 1. Effects of wogonin on cell viability and morphologic changes in U-2 OS cells. (A) U-2 OS cells were incubated in the absence or presence of the $10,50,75,100$ and $150 \mu \mathrm{M}$ wogonin for 24 and $48 \mathrm{~h}$. Cell viability was determined by using a PI exclusion method and flow cytometry. (B) Wogonin affected the morphologic changes in U-2 OS cells after treatment without and with 50, 75 and $100 \mu \mathrm{M}$ of wogonin for 24-h treatment. Cells were examined and photographed under a contrast-phase microscope. All data are expressed as the mean \pm SD (each in triplicate). a, $p<0.05$, significantly different when compared with DMSO-treated control; b, c and d, p $<0.05$, significantly different when compared with 50,75 and $100 \mu \mathrm{M}$ of wogonin exposure, respectively, by one-way ANOVA followed by Bonferroni's multiple-comparison test.

Statistical analysis. All data are shown as the means \pm SD of three independent experiments. The difference between the wogonin-treated and control groups were analyzed by one-way ANOVA followed by Bonferroni's multiple comparison test to examine the significance of differences and a value of $p<0.05$ was considered significant.

\section{Results}

Effects of wogonin on cell viability and morphological changes in the U-2 OS human osteosarcoma cells. After cells were exposed to various concentrations of wogonin for 24 and $48 \mathrm{~h}$, the percentage of total viable cells and cell morphological changes were examined. Results are shown in Fig. 1 and indicated that wogonin decreased the percentage of viable U-2 OS cells dose- and time-dependently (Fig. 1A). The wogonin at $150 \mu \mathrm{M}$ significantly decreased by 80 and $84 \%$ the viable cells at 24- and 48-h treatment, respectively (Fig. 1A). Results from the examining of a phase-contrast microscope indicated that wogonin induced cell morphological changes (Fig. 1B) and some of the treated cells showed changed shape and debris.

Effects of wogonin on DNA content and chromatin condensation in $\mathrm{U}-2 \mathrm{OS}$ cells. The results from flow cytometric analysis are shown in Fig. 2A, which indicated that exposing U-2 OS cells to $75 \mu \mathrm{M}$ wogonin for 24 and $48 \mathrm{~h}$ enhanced the percentage of sub-G1 population (apoptosis) in a dose-dependent manner (Fig. 2A), indicating that wogonin induced apoptotic death in U-2 OS cells. In order to confirm the occurrence of apoptosis in U-2 OS cells after treatment with wogonin, cells were also stained by DAPI because apoptotic cells were recognized by the condensed, fragmented, degraded nuclei and apoptotic body. Results shown in Fig. 2B and C indicated that wogonin induced chromatin condensation and apoptosis in a dosedependent manner.

Effects of wogonin on the levels of ROS productions, loss of $\Delta \Psi \mathrm{m}$ level and intracellular $\mathrm{Ca}^{2+}$ release in $\mathrm{U}-2$ OS cells. To confirm the possibility that the wogonin-induced apoptosis could be related to contributions from the ER stress and mitochondrial signal pathways, U-2 OS cells were treated with $75 \mu \mathrm{M}$ wogonin for the indicated periods of time, the productions of ROS and $\mathrm{Ca}^{2+}$ and the changes of $\Delta \Psi m$ were examined, the quantities and results are shown in Fig. 3. Results from the flow cytometric assay indicated that wogonin promoted the productions of ROS (Fig. 3A) and $\mathrm{Ca}^{2+}$ (Fig. 3C), but it diminished the level of $\Delta \Psi m$ (Fig. 3B). In contrast, administration of wogonin resulted in a right shift of the DCF and Flou-3 fluorescence curves, indicating the increase in ROS (Fig. 3A) and $\mathrm{Ca}^{2+}$ release (Fig. 3C), but in the left shift of DiOC6 fluorescence curves (a decrease in the level of fluorescence curves).

Effects of wogonin on caspase-3 activity of U-2 OS cells. To evaluate whether or not wogonin-induced apoptosis is involved in activation of caspase-3, this study investigated the caspase-3 activity by flow cytometric analysis. The results are shown in Fig. 4, and wogonin at the concentration of $75 \mu \mathrm{M}$ stimulated caspase-3 activity in a time-dependent manner (Fig. 4).

Effects of wogonin on the levels of apoptosis-associated proteins in U-2 OS cells. To confirm that wogonin-induced apoptosis of U-2 OS cells as noted in flow cytometric assays, cells were cultured for $0,6,12,24$, and $48 \mathrm{~h}$ in the presence of the $1 \%$ DMSO vehicle alone or $75 \mu \mathrm{M}$ wogonin. Cells were harvested for Western blot analysis regarding to the extrinsic, intrinsic and ER stress pathway-related proteins expression. Results are shown in Fig. 5, which indicated that wogonin promoted the levels of Bad and Bax (Fig. 5A), cytochrome $c$, caspase-9 and -3 active form, AIF and Endo G (Fig. 5B), Fas/ CD95 and caspase-8 (Fig. 5C), GADD153, GRP78, ATF-6 $\alpha$, calpin 1, calpin 2 and caspase-4 (Fig. 5D), but it decreased the level of Bcl-2 (Fig. 5A). Based on these results, we suggest that wogonin-induced cell death in U-2 OS cells might be mediated through ER stress- and mitochondria- and caspase cascadedependent apoptotic signaling multiple pathways. 
A
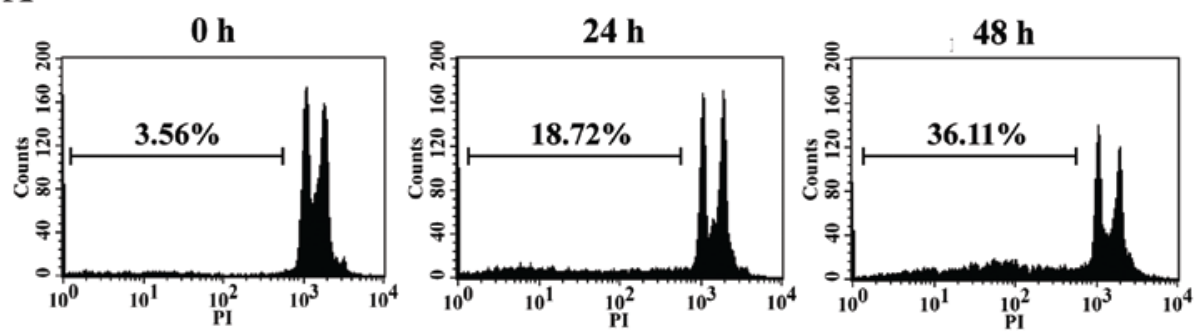

B
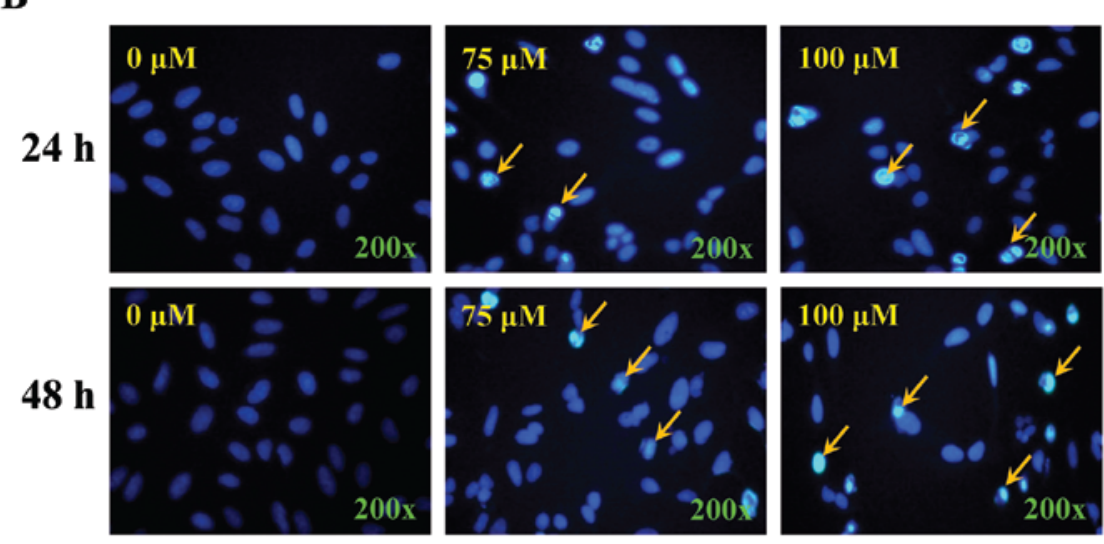

C

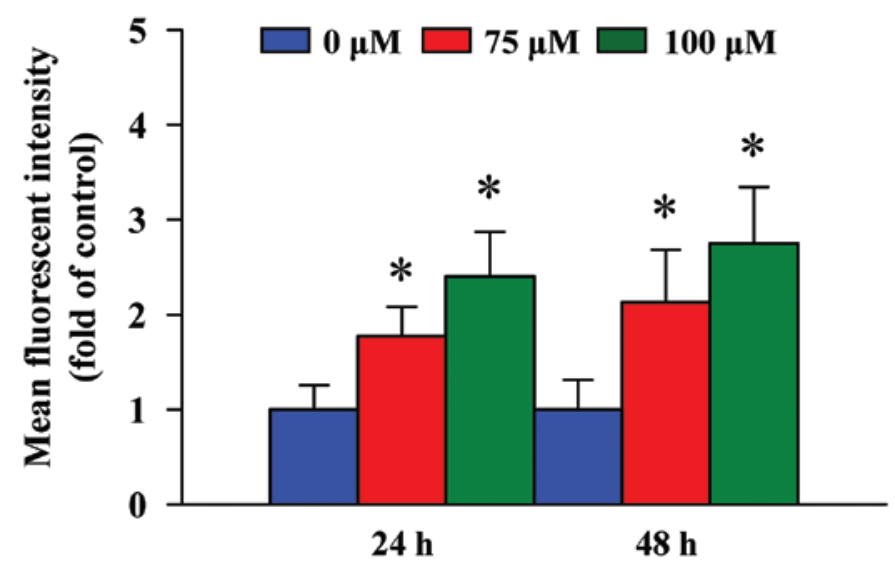

Time of incubation

Figure 2. Effects of wogonin on DNA content and chromatin condensation in U-2 OS cells. (A) Cells were cultured for 24 and $48 \mathrm{~h}$ in the presence of $75 \mu \mathrm{M}$ wogonin. In the time-dependent effects on sub-G1 population (apoptosis), U-2 OS cells were analyzed for DNA content by flow cytometry. (B) Cells were incubated without or with wogonin $(75$ and $100 \mu \mathrm{M})$ for 24 and $48 \mathrm{~h}$. An apoptotic catachrestic (chromatin condensation) was determined by DAPI staining and observed by using a fluorescence microscope. (C) Quantification of the data from mean fluorescence density was performed as the mean \pm SD ( $n=3$ ). The asterisks $\left.{ }^{*}\right)$ show the statistically significant differences $(\mathrm{p}<0.05)$ between wogonin-treated groups and the control $(0 \mu \mathrm{M})$. Statistical significance was assessed by one-way ANOVA followed by Bonferroni's multiple comparison test.

\section{Discussion}

It is documented that a good strategy for killing cancer cells is to induce cell apoptosis. Cell apoptotic pathway can be divided into the extrinsic pathway and intrinsic pathway including caspase-dependent and -independent pathway (28-30). The extrinsic pathway is initiated by ligation of trans-membrane death receptors such as Fas with ligands such as FasL to activate caspase- 8 then to activate caspase- 3 for causing apoptosis (31). The intrinsic pathway requires disruption of the mitochondrial membrane and the release of cytochrome $c$ from the mitochondrial to work together with Apaf-1 (apoptotic protease activating factor-1) and procaspase- 9 to promote the activation of caspase- 9 and thereby initiating the apoptotic caspase cascade $(29,32,33)$. Another pathway is named unfolded protein response (UPR) or ER stress pathway, a variety of toxic insults can result in ER stress that ultimately leads to apoptosis (34).

Herein, our results indicated that wogonin induced cell morphological changes, decreased the percentage of viable cells and induced apoptosis in U-2 OS cells. Furthermore, we used flow cytometry and results indicated that wogonin promoted the production of ROS and $\mathrm{Ca}^{2+}$, but it decreased the level of $\Delta \Psi m$ in U-2 OS cells. Disruption of mitochondrial membrane potential is considered to be an indicator of mitochondria damage and generally is defined as an early 
A
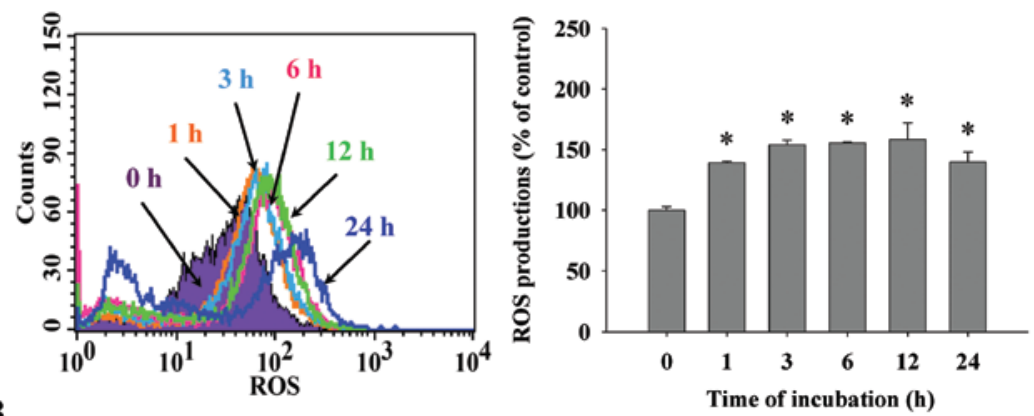

B
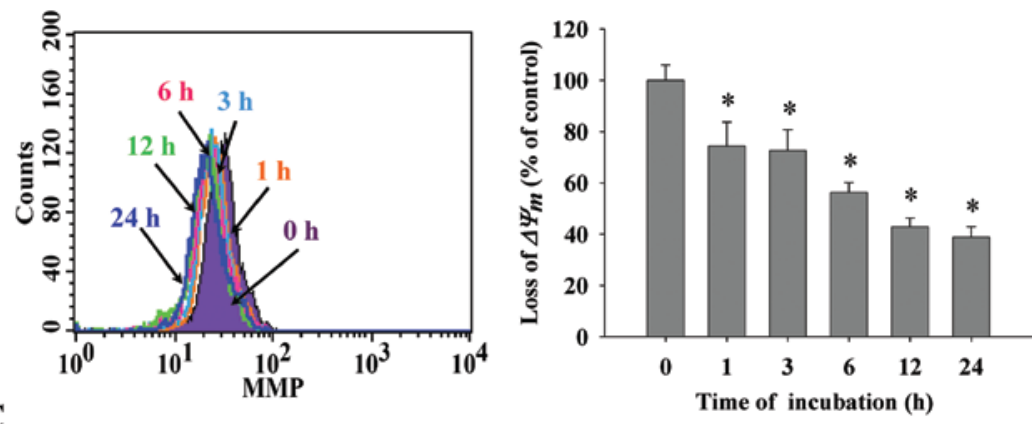

C
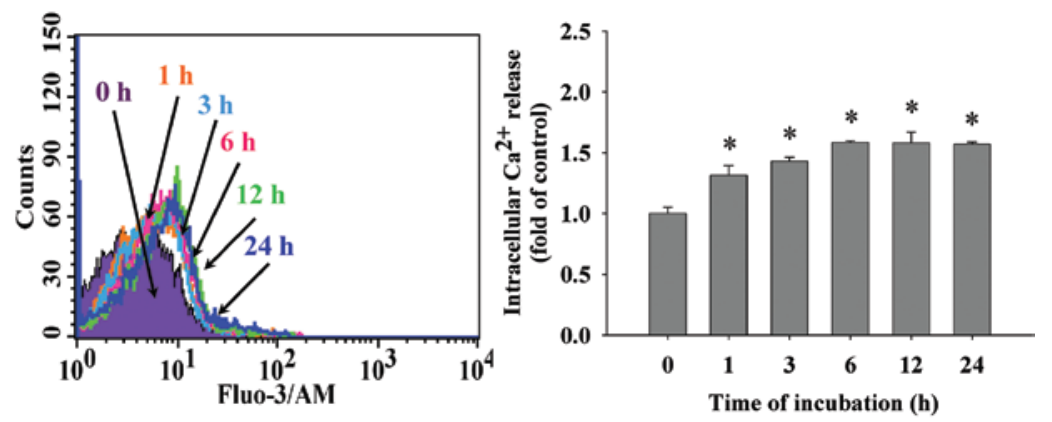

Figure 3. Effects of wogonin on the ROS production, loss of $\Delta \Psi m$ levels and intracellular $\mathrm{Ca}^{2+}$ release in $\mathrm{U}-2$ OS cells. Cells were incubated without and with $75 \mu \mathrm{M}$ wogonin for $1,3,6,12$ and $24 \mathrm{~h}$. The examined cells were stained individually by DCFH-DA dye for ROS (A), DiOC 6 for $\Delta \Psi m(\mathrm{~B})$ and Flou-3/AM dye for intracellular $\mathrm{Ca}^{2+}(\mathrm{C})$ and results were determined and quantied by flow cytometry and BD CellQuest Pro software. Data are expressed as mean \pm SD of three independent experiments. *Significantly different $(\mathrm{p}<0.05)$ compared with the untreated control sample $(0 \mathrm{~h})$. Statistical significance was assessed by one-way ANOVA followed by Bonferroni's multiple comparison test.

A
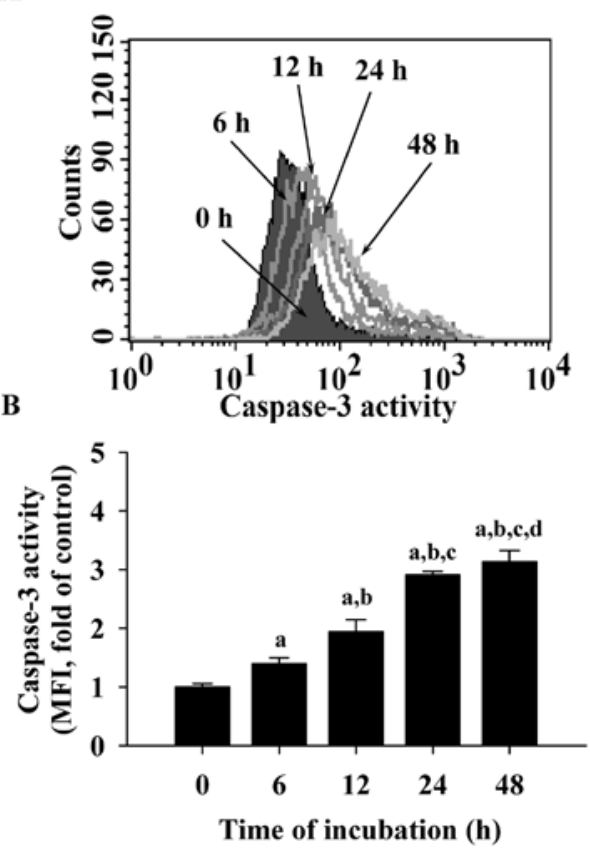

stage of apoptosis, preceding efflux of small molecules from the mitochondria (including cytochrome $c$, apoptosis-inducing factor, and cIAPs) and followed by caspase-9/-3 cascade activation (35). Western blot analysis also showed that wogonin promoted the levels of GADD153, GRP78 and caspase- 4 which are vital features for unfolded protein response (UPR) and meant that wogonin induced apoptosis through the ER stress/calpain signaling pathway. It was reported that wogonin did not cause apoptosis or decreased viability, even at the highest tested concentration $(100 \mathrm{mM})$

Figure 4. Effects of wogonin on caspase- 3 activity of U-2 OS cells. (A) Wogonin stimulated the activity of caspase- 3 in U-2 OS cells. Cells were exposed to $75 \mu \mathrm{M}$ wogonin for $0,6,12,24$ and $48 \mathrm{~h}$ and then the level of caspase- 3 activity was determined by flow cytometry. (A) The representative profile from flow cytometric analysis; (B) Caspase-3 activity (mean fluorescence index, MFI). a, $\mathrm{p}<0.05$, is significantly different compared with control ( $0 \mathrm{~h})$; b, c and d, p $<0.05$, shows significant difference compared with 6, 12 and 24-h danthron treatment groups, respectively, by one-way ANOVA followed by Bonferroni's multiple comparison test. 
A

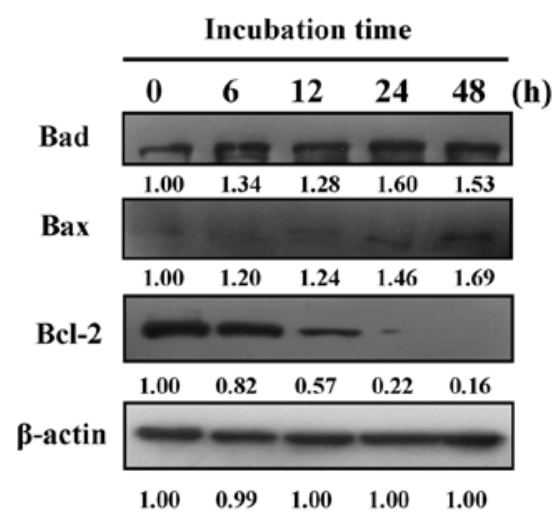

C

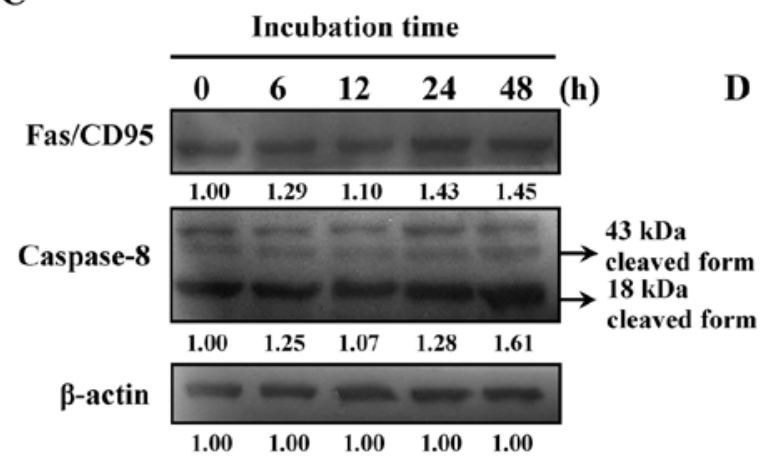

B

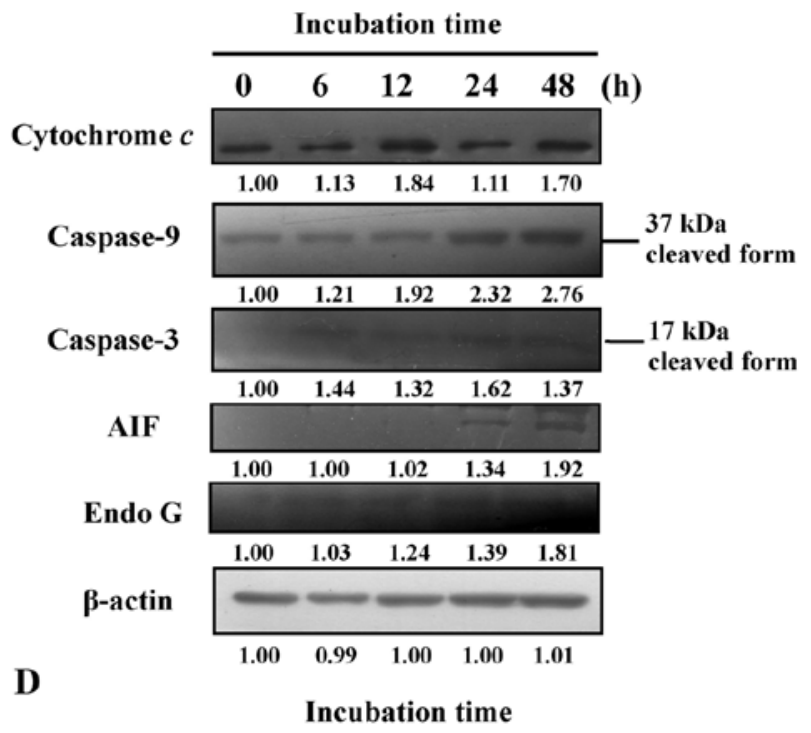

GADD153 $\begin{array}{llllll}0 & 6 & 12 & 24 & 48 & \text { (h) }\end{array}$

GRP78

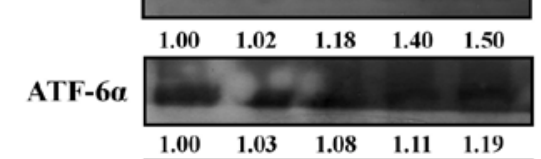

\begin{tabular}{l|llllll|}
\cline { 2 - 7 } Calpain 1 & & & & & \\
\cline { 2 - 7 } & & & & & & \\
\hline & 1.00 & 1.34 & 2.44 & 3.05 & 3.76 \\
\cline { 2 - 6 } & & & & &
\end{tabular}

Calpain 2
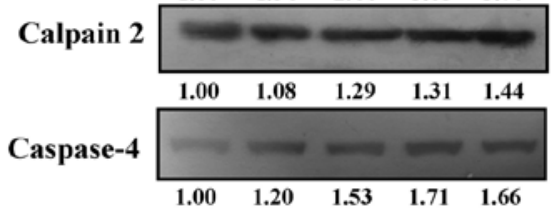

$\beta$-actin

Figure 5. Effects of wogonin on the levels of apoptosis-associated proteins in U-2 OS cells. (A) After $75 \mu \mathrm{M}$ of wogonin for 0,6, 12, 24 and 48-h treatment, cells were harvested and lysed for the evaluation of the associated-protein levels. Primary antibodies for Bad, Bax and Bcl-2 (A), cytochrome $c$, caspase-9, caspase-3, AIF and Endo G (B), Fas and caspase-8 (C), and GADD153, GRP78, ATF-6 $\alpha$, calpain 1, calpain 2 and caspase-4 (D) were examined by Western blot analysis. $\beta$-actin as an internal control.

in normal human prostate epithelial PrEC cells (10). Thus being a chemoprevention agent that should be able to eliminate cancer cells without any toxicity to normal cells.

It was reported that GADD153 and GRP78 is a hallmark of ER stress (36). Flow cytometric assay also showed that wogonin induced dysfunction of mitochondria (loss of mitochondrial membrane potential) (Fig. 3B). The results from Western blotting also showed that wogonin increased the levels of Bad and Bax, and it decreased the level of Bcl-2, leading to the changes of the ratio of $\mathrm{Bax} / \mathrm{Bcl}-2$ for causing loss of $\Delta \Psi \mathrm{m}$. It was reported that promotion of the ratio of $\mathrm{Bax} / \mathrm{Bcl}-2$ decreased the level of mitochondrial membrane potential (37). The loss of the outer mitochondrial membrane integrity and the release of cytochrome $c$ from the mitochondria to the cytosol, the cells are committed to apoptosis $(38,39)$. It was reported that wogonin induced p53 expression then led to PUMA, Bax elevation for causing apoptosis (10). The productions of ROS contribute to mitochondrial damage that may facilitate the further release of ROS into the cytoplasm $(38,39)$.

It is well known that the study of apoptosis reveals that many oncogenes and tumor suppressor genes are involved in mediating apoptosis $(4,40)$. Thus, we further investigated whether apoptosis-related protein levels were involved in wogonin-induced apoptosis in U-2 OS cells. In particular, the levels of caspase-8, -9 and -3 or -4 have been elevated compared to the untreated control. And the results indicated that wogonin promoted the levels of caspase- $9,-3,-8$ and -4 (Fig. 5B-D) and it also promoted the level of Fas/CD95. These data indicated that wogonin induced apoptosis through extrinsic and intrinsic signaling pathways, and wogonintreated U-2 OS cells were involved in ER stress signaling 


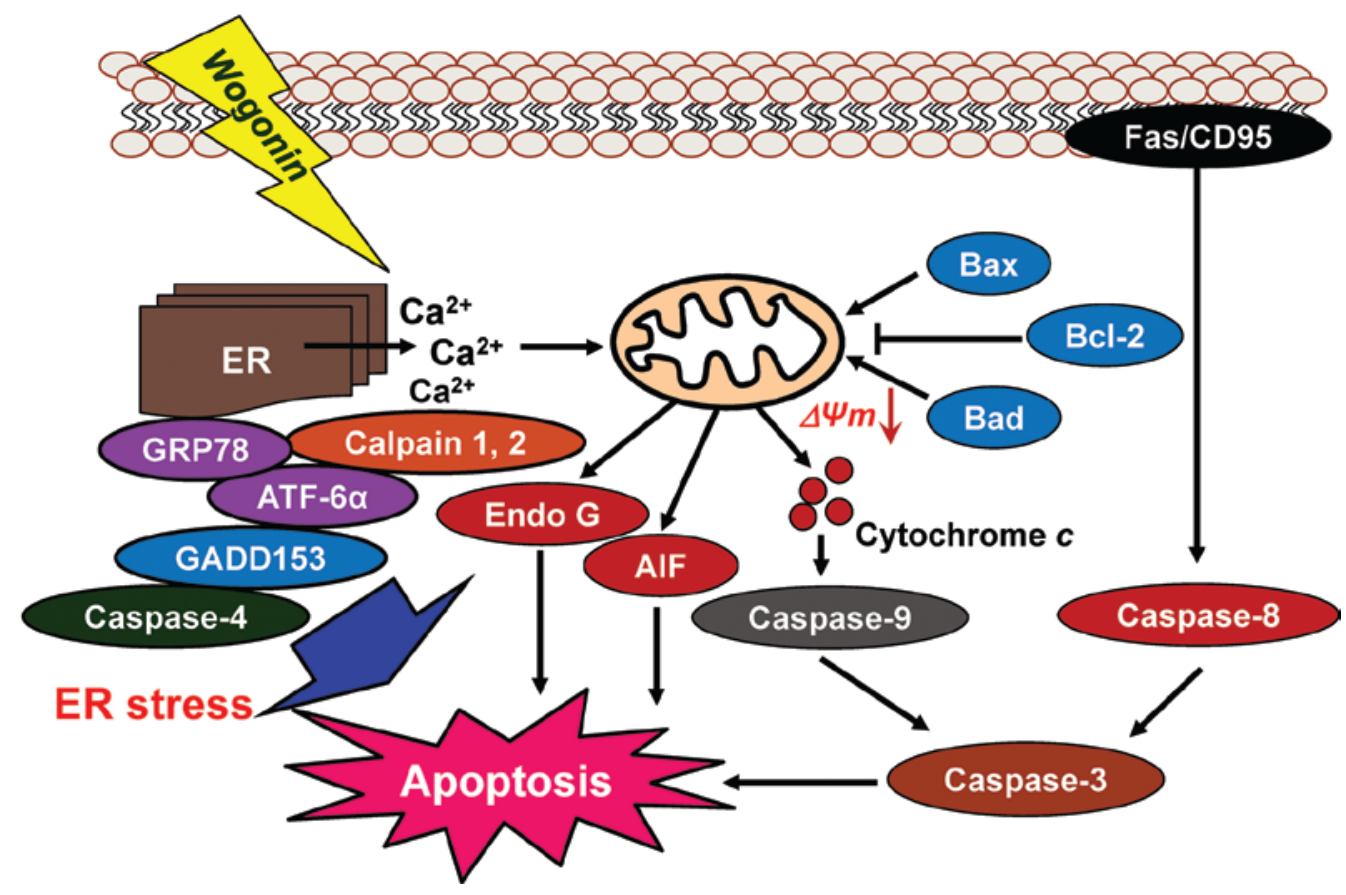

Figure 6. Proposed signal model for wogonin-mediated apoptosis in U-2 OS human osteosarcoma cells. Wogonin increases production of ROS and intracellular $\mathrm{Ca}^{2+}$ levels, resulting in stimulation of Bax and Bad protein expressions and reduction of Bcl-2. The $\Delta \Psi m$ is then reduced and cytochrome $c$ is released, which activates caspases-9 and -3 producing apoptosis in the U-2 OS cell line. Also, wogonin-triggered apoptotic cell death is involved in ER stress and activated the expression of ER stress-related proteins such as GADD153, GRP78, ATF-6 $\alpha$, calpain 1, calpain 2 and caspase-4, leading to unfolded protein response and apoptosis in U-2 OS cells.

pathway. The caspase-independent pathway of intrinsic apoptosis was also triggered by the increase of AIF and Endo $\mathrm{G}$ protein levels (Fig. 5B). Due to cytochrome $c$ and caspase-9 elevation, the caspase-dependent pathway of intrinsic apoptosis may play important roles in cell apoptosis $(41,42)$. It was reported that caspases are a family of cysteine proteases that play a central role during the executional phase of apoptosis (43). Flow cytometric assay also showed that wogonin promoted the caspase-3 activity in U-2 OS cells (Fig. 4).

Substantial evidence has showed that wogonin triggered apoptosis in many human cancer cells, and the involvement of GADD153 in wogonin induced apoptosis in U-2 OS cells is still unclear. Herein, we conclude that GADD153 sensitizes cells to ER stress through the down-regulation of Bcl-2 and enhanced oxidant injury. GRP78 is also an endoplasmic reticulum chaperone protein and wogonin also promoted the levels of GRP78 and ATF-6 $\alpha$ in U-2 OS cells (Fig. 5D). Our novel findings suggest that these events represented that extrinsic, intrinsic and ER stress apoptotic pathways were all induced by wogonin in vitro.

The present report describes the selective in vitro killing of U-2 OS cells by wogonin and the anticancer activity (induction of apoptotic cell death). In conclusion, the wogonininduced apoptotic events can be summarized by the sequence presented in Fig. 6. In this proposed signal model, wogoninmediated ROS generation led to ER stress representing the central trigger for activation of the apoptotic cascade. Furthermore, results indicated that wogonin promoted the generation of ROS and a decrease in $\Delta \Psi m$, as well as in elevation of Bax and reduction of Bcl-2 levels. The movement of Bax to the mitochondria reduced the $\Delta \Psi m$, an event that results in the release of cytochrome $\mathrm{c}$, subsequent activation of caspase-9 and -3 , AIF and Endo G release from mitochondria and consequently cleaved specific substrates leading to apoptotic changes. These findings might aid in the understanding of the mode of actions of the wogonin and provide a theoretical basis for the therapeutic use of this compound in osteosarcoma in the future.

\section{Acknowledgement}

This study was supported by a Grant Research project 9907 from Central Region Hospital Alliance, Department of Health, Executive Yuan, R.O.C. (Taiwan) and in part by Taiwan Department of Health Clinical Trial and Research Center of Excellence (DOH100-TD-B-111-004).

\section{References}

1. Chen X, Ko LJ, Jayaraman L and Prives C: p53 levels, functional domains, and DNA damage determine the extent of the apoptotic response of tumor cells. Genes Dev 10: 2438-2451, 1996.

2. Yu Z, Chen J, Ford BN, Brackley ME and Glickman BW: Human DNA repair systems: an overview. Environ Mol Mutagen 33: 3-20, 1999

3. Barry MA, Behnke CA and Eastman A: Activation of programmed cell death (apoptosis) by cisplatin, other anticancer drugs, toxins and hyperthermia. Biochem Pharmacol 40: 2353-2362, 1990.

4. Hoffman B and Liebermann DA: Molecular controls of apoptosis: differentiation/growth arrest primary response genes, protooncogenes, and tumor suppressor genes as positive and negative modulators. Oncogene 9: 1807-1812, 1994.

5. Chi YS, Cheon BS and Kim HP: Effect of wogonin, a plant flavone from Scutellaria radix, on the suppression of cyclooxygenase- 2 and the induction of inducible nitric oxide synthase in lipopolysaccharide-treated RAW 264.7 cells. Biochem Pharmacol 61: 1195-1203, 2001 
6. Lee H, Kim YO, Kim H, et al: Flavonoid wogonin from medicinal herb is neuroprotective by inhibiting inflammatory activation of microglia. FASEB J 17: 1943-1944, 2003.

7. Shieh DE, Liu LT and Lin CC: Antioxidant and free radical scavenging effects of baicalein, baicalin and wogonin. Anticancer Res 20: 2861-2865, 2000.

8. Chung H, Jung YM, Shin DH, et al: Anticancer effects of wogonin in both estrogen receptor-positive and -negative human breast cancer cell lines in vitro and in nude mice xenografts. Int J Cancer 122: 816-822, 2008.

9. Parajuli P, Joshee N, Rimando AM, Mittal S and Yadav AK: In vitro antitumor mechanisms of various Scutellaria extracts and constituent flavonoids. Planta Med 75: 41-48, 2009.

10. Lee DH, Kim C, Zhang L and Lee YJ: Role of p53, PUMA, and Bax in wogonin-induced apoptosis in human cancer cells. Biochem Pharmacol 75: 2020-2033, 2008.

11. Chen YC, Shen SC, Lee WR, et al: Wogonin and fisetin induction of apoptosis through activation of caspase 3 cascade and alternative expression of p21 protein in hepatocellular carcinoma cells SK-HEP-1. Arch Toxicol 76: 351-359, 2002.

12. Li DR, Hou HX, Zhang W and Li L: Effects of wogonin on inducing apoptosis of human ovarian cancer A2780 cells and telomerase activity. Ai Zheng 22: 801-805, 2003.

13. Wang W, Guo QL, You QD, et al: The anticancer activities of wogonin in murine sarcoma S180 both in vitro and in vivo. Biol Pharm Bull 29: 1132-1137, 2006.

14. Lu KH, Lue KH, Chou MC and Chung JG: Paclitaxel induces apoptosis via caspase-3 activation in human osteogenic sarcoma cells (U-2 OS). J Orthop Res 23: 988-994, 2005.

15. Tan TW, Tsai HR, Lu HF, et al: Curcumin-induced cell cycle arrest and apoptosis in human acute promyelocytic leukemia HL-60 cells via MMP changes and caspase- 3 activation. Anticancer Res 26: 4361-4371, 2006.

16. Hsu SC, Kuo CL, Lin JP, et al: Crude extracts of Euchresta formosana radix induce cytotoxicity and apoptosis in human hepatocellular carcinoma cell line (Hep3B). Anticancer Res 27: 2415-2425, 2007.

17. Lu HF, Wang HL, Chuang YY, et al: Danthron induced apoptosis through mitochondria- and caspase-3-dependent pathways in human brain glioblastoma multiforms GBM 8401 cells. Neurochem Res 35: 390-398, 2010.

18. Kuo JH, Chu YL, Yang JS, et al: Cantharidin induces apoptosis in human bladder cancer TSGH 8301 cells through mitochondriadependent signal pathways. Int J Oncol 37: 1243-1250, 2010.

19. Su CC, Lin JG, Li TM, et al: Curcumin-induced apoptosis of human colon cancer colo 205 cells through the production of $\mathrm{ROS}, \mathrm{Ca}^{2+}$ and the activation of caspase-3. Anticancer Res 26: 4379-4389, 2006.

20. Wu SH, Hang LW, Yang JS, et al: Curcumin induces apoptosis in human non-small cell lung cancer NCI-H460 cells through ER stress and caspase cascade- and mitochondria-dependent pathways. Anticancer Res 30: 2125-2133, 2010.

21. Lo C, Lai TY, Yang JH, et al: Gallic acid induces apoptosis in A375.S2 human melanoma cells through caspase-dependent and -independent pathways. Int J Oncol 37: 377-385, 2010

22. Kuo HM, Tsai HC, Lin YL, et al: Mitochondrial-dependent caspase activation pathway is involved in baicalein-induced apoptosis in human hepatoma J5 cells. Int J Oncol 35: 717-724, 2009.

23. Liu KC, Huang YT, Wu PP, et al: The roles of AIF and Endo G in the apoptotic effects of benzyl isothiocyanate on DU 145 human prostate cancer cells via the mitochondrial signaling pathway. Int J Oncol 38: 787-796, 2011.
24. Chiang JH, Yang JS, Ma CY, et al: Danthron, an anthraquinone derivative, induces DNA damage and caspase cascades-mediated apoptosis in SNU-1 human gastric cancer cells through mitochondrial permeability transition pores and Bax-triggered pathways. Chem Res Toxicol 24: 20-29, 2011.

25. Lu CC, Yang JS, Huang AC, et al: Chrysophanol induces necrosis through the production of ROS and alteration of ATP levels in J5 human liver cancer cells. Mol Nutr Food Res 54: 967-976, 2010.

26. Yu FS, Yang JS, Yu CS, et al: Safrole induces apoptosis in human oral cancer HSC-3 cells. J Dent Res 90: 168-174, 2011.

27. Shen JK, Du HP, Yang M, Wang YG and Jin J: Casticin induces leukemic cell death through apoptosis and mitotic catastrophe. Ann Hematol 88: 743-752, 2009.

28. Chen $\mathrm{M}$ and Wang J: Initiator caspases in apoptosis signaling pathways. Apoptosis 7: 313-319, 2002

29. Budihardjo I, Oliver H, Lutter M,Luo X and Wang X: Biochemical pathways of caspase activation during apoptosis. Annu Rev Cell Dev Biol 15: 269-290, 1999.

30. Rao RV, Ellerby HM and Bredesen DE: Coupling endoplasmic reticulum stress to the cell death program. Cell Death Differ 11: 372-380, 2004

31. Salvesen GS and Duckett CS: IAP proteins: blocking the road to death's door. Nat Rev Mol Cell Biol 3: 401-410, 2002.

32. Earnshaw WC, Martins LM and Kaufmann SH: Mammalian caspases: structure, activation, substrates, and functions during apoptosis. Annu Rev Biochem 68: 383-424, 1999.

33. Strasser A, O'Connor L and Dixit VM: Apoptosis signaling. Annu Rev Biochem 69: 217-245, 2000.

34. Rao RV, Hermel E, Castro-Obregon S, et al: Coupling endoplasmic reticulum stress to the cell death program. Mechanism of caspase activation. J Biol Chem 276: 33869-33874, 2001.

35. Castanier $\mathrm{C}$ and Arnoult D: Mitochondrial dynamics during apoptosis. Med Sci (Paris) 26: 830-835, 2010.

36. Kim R, Emi M, Tanabe K and Murakami S: Role of the unfolded protein response in cell death. Apoptosis 11: 5-13, 2006.

37. Scorrano L, Oakes SA, Opferman JT, et al: BAX and BAK regulation of endoplasmic reticulum $\mathrm{Ca}^{2+}$ : a control point for apoptosis. Science 300: 135-139, 2003.

38. Di Giovanni S, Mirabella M, Papacci M, Odoardi F, Silvestri G and Servidei S: Apoptosis and ROS detoxification enzymes correlate with cytochrome c oxidase deficiency in mitochondrial encephalomyopathies. Mol Cell Neurosci 17: 696-705, 2001.

39. Lee MG, Lee KT, Chi SG and Park JH: Costunolide induces apoptosis by ROS-mediated mitochondrial permeability transition and cytochrome c release. Biol Pharm Bull 24: 303-306, 2001.

40. Oren M: The involvement of oncogenes and tumor suppressor genes in the control of apoptosis. Cancer Metastasis Rev 11: 141-148, 1992.

41. Suzuki M, Endo M, Shinohara F, Echigo S and Rikiishi H: Differential apoptotic response of human cancer cells to organoselenium compounds. Cancer Chemother Pharmacol 66: 475-484, 2010.

42. Diwakarla S, Nagley P, Hughes ML, Chen B and Beart PM: Differential insult-dependent recruitment of the intrinsic mitochondrial pathway during neuronal programmed cell death. Cell Mol Life Sci 66: 156-172, 2009.

43. Vaux DL and Korsmeyer SJ: Cell death in development. Cell 96: 245-254, 1999 . 